\title{
La potencia normativa europea en relación con el caso iraní entre 2010 y 2017: el Plan de Acción Integral Conjunto
}

\author{
Miguel García Amorós ${ }^{1}$ \\ Universidad Autónoma de Barcelona \\ Recibido: 17/10/2019 - Aprobado 2/12/2019 \\ DOI: https://doi.org/10.22490/26655489.3420
}

\section{Resumen}

La Unión Europea (UE) es considerada una potencia normativa por una parte de los estudios europeos. Ian Manners es el precursor de dicha aproximación, que entiende a la UE como un proyecto político sui generis que es capaz de imprimir sus percepciones de normalidad al resto de la sociedad internacional. El presente artículo estudia en qué modo Bruselas ha ejercido como potencia normativa en el desarrollo de las negociaciones para la consecución del acuerdo nuclear con Irán. Apoyado en la base teórica presentada por Manners, el artículo estudia no solo qué valores y principios ha introducido la UE en el proceso negociador con Teherán sino de qué modo ha tratado de hacerlo bajo el análisis documental y la consulta de fuentes primarias y secundarias. La UE podrá ser considerada una potencia normativa en este caso solo al entender que ha decidido priorizar la exportación de uno de sus compromisos normativos con el régimen de no proliferación nuclear en detrimento de otros, en este caso la democracia y la promoción de los derechos humanos. El delicado momento por el que atraviesa el acuerdo nuclear con Irán pone a la UE en una situación que puede reafirmar su papel como potencia normativa defensora del multilateralismo.

Palabras clave: multilateralismo, potencia normativa europea, régimen de no proliferación nuclear.

1 Máster en Relaciones Internacionales, Seguridad y Desarrollo, Universidad Autónoma de Barcelona, Barcelona, España. miguel.garciaam-campus@uab.cat. 


\section{Introducción}

El presente artículo tiene como objetivo estudiar el desarrollo del concepto de potencia normativa europea, sus planteamientos y limitaciones. Para ello se pretende someter a análisis las tesis de Ian Manners (2002), en tanto que precursor de dicha aproximación teórica dentro de los estudios europeos. El marco referencial del concepto de potencia normativa será utilizado para analizar el papel de la Unión Europea (UE) en la consecución y negociación del Plan de Acción Integral Conjunto (PAIC) alcanzado con Irán en 2015. El objetivo es identificar qué elementos normativos ha tratado de introducir la UE en el desarrollo del proceso, siempre vinculado con las consecuencias de este acuerdo en la arquitectura global del régimen de no proliferación.

Desde una perspectiva más amplia, también se persigue entender qué implicaciones tiene para la UE la consecución del PAIC y su mantenimiento, más aún cuando el acuerdo se encuentra en una situación crítica tras haber sido rechazado por Ios EE. UU. El rol de la UE como actor internacional, su concepción de la sociedad internacional y su posición dentro de la misma están relacionadas con su intervención en el proceso negociador con Irán. Nos planteamos pues en qué medida ha actuado la UE como potencia normativa en el caso iraní y qué elementos normativos ha introducido en el mismo caso.

Así las cosas, se mantiene que la UE se ha servido del caso iraní para actuar como potencia normativa introduciendo sus percepciones de la paz sostenible y el Estado de derecho supranacional. Asimismo, el caso iraní ha posibilitado a la UE postularse como una potencia comprometida con el multilateralismo.

El presente trabajo realizará un recorrido por el desarrollo académico del concepto de potencia normativa europea. Más tarde estudiará la evolución de la presencia de la UE en las distintas negociaciones con Irán hasta la consecución del PAIC. Posteriormente recogerá los diferentes elementos normativos que la UE haya podido introducir a lo largo del proceso negociador. Finalmente se ofrecerán unas conclusiones. 


\section{La potencia normativa europea: desarrollo y evolución teórica}

Desde que Ian Manners lo introdujese en 2002, el concepto de potencia normativa para hacer referencia a la UE se ha convertido en una referencia fundamental de la discusión académica encaminada a definir a la Unión en su vertiente de actor internacional. El autor persigue con su propuesta contribuir a un mejor entendimiento sobre cuáles son los principios que la UE promueve y cómo la UE actúa, tratando a la vez de analizar y juzgar el poder normativo ejercido desde Bruselas para con el resto de los actores internacionales (Manners, 2008, 66).

Manners estudia la habilidad de dar forma a las concepciones de lo "normal" en las relaciones internacionales (Manners, 2002, 239). El marco de la potencia normativa europea pone el foco en el análisis de aquello que la UE quiere entender como "normalidad" internacional y de qué modo pretende proyectarlo. Este planteamiento analítico requiere la consideración en el examen de elementos tales como los procesos cognitivos y sus componentes sustantivos y simbólicos. El autor considera además que no es pertinente estudiar el componente ético de la acción exterior de la UE fuera del concepto de potencia normativo (Manners, 2002, 239).

La UE es resultado de un proyecto que surge como oposición a cualquier atisbo de conflicto violento entre los Estados europeos. Esta singularidad histórica ha contribuido a que la Unión haya evolucionado hacia un híbrido de formas de gobernanza supranacional e internacional que trasciende las normas westfalianas clásicas (King, 1999, 313). No resulta extraño que esta nueva forma de articulación política haya desarrollado ciertos principios que son comunes a todos los Estados miembros. Dicha apelación a las normas y principios universales ha ido tomando, en el periodo de posguerra fría, cada vez un mayor peso no solo en la relación de la UE con sus Estados miembros sino con el resto del mundo. La UE ha edificado su identidad como actor internacional en torno a dichos valores y a la difusión de normas en el sistema internacional (Noureddine, 2016; De Zutter, 2010). Este hecho supone un elemento diferenciador con respecto al carácter de actores internacionales tradicionales como los Estados, que actúan según patrones más centrados en aspectos securitizantes (Hyde-Pride, 2008, 30). 
El planteamiento de Manners se articula en torno a la presencia de nueve principios normativos de los que la UE participa y promueve. Estos son, la paz, la libertad, el Estado de derecho, la solidaridad social, la antidiscriminación, el desarrollo sostenible y la buena gobernanza (Manners, 2002, 240). Para el caso que nos ocupa cobra especial relevancia el estudio de la aproximación europea hacia la paz y al Estado de derecho. Dichos principios se encuentran vinculados al desarrollo del conflicto con Irán y a las paulatinas tentativas de resolución en las que la UE ha participado.

El mantenimiento de un contexto de paz se encuentra en las raíces del proyecto de integración europeo. Manners (2006, 33) propone una interpretación a la europea que enfatiza la dimensión sostenible de la paz. Las políticas comunitarias sitúan la ayuda al desarrollo, el comercio, la cooperación, el diálogo político, la cooperación regional e incluso los propios procesos de ampliación en el núcleo de sus acciones destinadas a la prevención de conflictos (Manners, 2008, 69).

El Estado de derecho y su defensa se configura como uno de los principios elementales que guían la acción de la UE. Los valores y principios de la UE poseen una presencia destacada en los textos legales primarios de la Unión (Whitman, 2011, 2). Se observan referencias explícitas a los derechos humanos en los Tratados de Maastricht y Ámsterdam (Noureddine, 2016, 113) mientras Lisboa establece que la PESC y los demás elementos de la acción exterior deben estar orientados hacia la promoción externa de los principios y valores fundamentales de la Unión, entre ellos el Estado de derecho (Art. 21 del TUE). El hecho de que la UE realice una conexión entre su defensa del Estado de derecho y su respeto a la Carta de Naciones Unidas y al derecho internacional produce lo que Manners (2006, 35) considera Estado de derecho supranacional. El caso iraní supone el impulso a la participación de tanto la UE como sus Estados miembros del derecho internacional. El concepto de potencia normativa se encuentra vinculado al respeto y promoción del derecho internacional y al apoyo de regímenes internacionales (Sjursen, 2006, 244; Toje A., 2011:254).

Manners vincula el refuerzo y expansión normativa llevado a cabo por la UE con su voluntad de presentarse como un actor que va más allá de la suma de sus partes (Manners, 2002, 244). 
Este esfuerzo reivindicativo de su autonomía operacional busca obtener mayores cotas de legitimidad para el proyecto europeo. Se evidencia el carácter pragmático que la noción de potencia normativa tiene para la UE en tanto que la dota de especificidad como actor internacional y refuerza su legitimidad. Así acaba por crearse la sensación entre los Estados miembros de que en determinados escenarios la UE está dotada de un papel que trasciende y supera el de sus miembros. El caso iraní se configura como uno de estos espacios; en los Estados miembros consideraban el potencial negociador de la UE y se alineaban con él incluso en sus posicionamientos individuales (Dryburgh, 2008, 259).

Manners ha continuado a lo largo de su obra afianzando el concepto de potencia normativa europea con el objetivo de abonanzar su propuesta académica. El autor ha tratado de ir más allá del mero enunciado de principios y valores promovidos por la UE para analizar el modo en que se impulsan desde Bruselas (Manners, 2008, 66). A saber, en virtud de los principios de "vivir por ejemplo"; por deber de sus acciones en "ser razonable" y como consecuencia de su impacto en "hacer el menor daño". Javier Solana (2006), antiguo alto representante para la PESC, definió a la perfección el modo en que la UE impulsa la promoción de sus valores y principios: "lentamente y sobre la base de una asociación". Esta apreciación va a servir de ayuda en numerosas ocasiones en el intento de explicar la naturaleza de las actuaciones europeas puesto que reasegura la preferencia de la Unión por cambios progresivos cimentados en la conclusión de acuerdos.

En términos de reflexión sobre el poder normativo, la ética de la virtud nos alienta a mirar el carácter o rasgos que guían a la UE y sus Estados miembros en la búsqueda de acciones exteriores. La ética de la virtud y su énfasis en el carácter moral de los grupos sociales fomentan un enfoque que se detiene en el examen de virtudes como la benevolencia, la generosidad o la justicia. Tal reflexión implica examinar los medios a través de los cuales se establecen tales virtudes y la medida en que un grupo las comparte. El establecimiento de virtudes a través de la educación, la religión u otras prácticas sociales forma una parte importante de la comprensión de la base compartida del bien común (Manners, 2008, 76). 
Con base en el debate sobre la ética de la virtud se podría sugerir que cualquier ética normativa de la UE debería basarse en "vivir con el ejemplo virtuoso". "Vivir con el ejemplo" implica garantizar que la UE sea normativamente coherente y consistente en sus políticas (Manners, 2008, 76). La coherencia supone garantizar que la UE no solo promueve sus propias normas, sino que los principios que las constituyen y su acción exterior forman parte de una estrategia universalizable y holística para la paz mundial. Aquí las referencias a la Carta de las Naciones Unidas y a los diferentes regímenes internacionales adquieren relevancia en tanto que los principios promovidos por la UE encuentran sustento en el sistema internacional. La noción de poder normativo solo puede aplicarse de forma admisible bajo una condición: la consistencia entre políticas internas y prescripciones y actuaciones externas (Nicolaïdis y Nicolaïdis, 2006, 348).

En contraste con la ética de la virtud, un enfoque deontológico del poder normativo enfatiza la racionalización de los deberes y reglas que guían a la UE en su acción exterior. O'Neill (2000) y otros neokantianos buscan enfatizar el papel progresivo y expansivo del debate público y el razonamiento en la creación de los derechos y deberes que se consideran importantes dentro de un grupo. El conocimiento de la promoción de este tipo de comportamiento gobernado por reglas a través del derecho nacional e internacional es fundamental para dar sentido a esta idea compartida del bien común. La ética deontológica enfatiza los medios a través de los cuales las acciones son motivadas y practicadas (O'Neill, 2000, 52). A este respecto se subraya el establecimiento de la ley, incluidos los derechos y los deberes, como fórmula de búsqueda del bien común. Tanto los partidarios como los detractores de la UE han argumentado que se ha convertido en un "paraíso kantiano" regido tanto por el derecho nacional e internacional, como por el acervo comunitario.

Al centrar el debate en una ética deontológica se podría argumentar que cualquier esfuerzo normativo de la UE debería estar basado en el principio de "ser razonable" en la esfera internacional. "Ser razonable" implica garantizar que la UE razona y racionaliza su acción exterior a través de procesos de compromiso y diálogo. El compromiso supone iniciar e institucionalizar patrones regulares y transparentes de comunicación o asociación. El diálogo se entiende como la 
participación en procesos de deliberación y discusión bidireccional como parte del razonamiento de los méritos de la actividad exterior (Manners, 2008, 78).

Por último, la teorización del poder normativo mediante un enfoque consecuencial implica analizar los impactos de las acciones de la UE y sus implicaciones para terceros. El foco de este planteamiento se ubica en la interacción entre actores y sus consecuencias. La incidencia en el componente relacional de la acción exterior resulta de gran relevancia para los debates que surgen en torno al carácter de las relaciones entre la UE y el resto del mundo. De igual modo introduce el problema del pluralismo de valores y la medida en que los méritos de las diferentes consecuencias pueden ser en sí mismas elecciones morales.

La ética de las consecuencias nos lleva a la sugerencia de que la UE debería "hacer el menor daño" posible en la política mundial. "Hacer el menor daño" implica garantizar que la UE reflexiona sobre el impacto de sus políticas en los países y regiones con las que colabora, en particular fomentando la apropiación local y practicando una condicionalidad positiva. La apropiación local es crucial para garantizar que las relaciones generen capacidades alternativas y complementarias en los socios. La condicionalidad positiva sirve para evaluar si la UE está "haciendo el menor daño" en los lugares donde está tratando de actuar. Se pretende garantizar que el "progreso" sea recompensado con mayores incentivos y que los elementos opuestos, los de condicionalidad negativa, posean un carácter temporal y sean revertidos una vez se modifiquen los comportamientos susceptibles de generar dicha condicionalidad (Manners, 2008, 80).

La propuesta de Manners, tal y como se ha señalado, ha generado voces que han identificado algunas limitaciones y dudas con respecto su capacidad explicativa. Thomas Diez (2013) identifica cuatro grandes debates suscitados por el tratamiento de la UE como potencia normativa. El primero de ellos surge en torno a la cuestión de si la acción exterior de la UE está movida por normas o por intereses. Asimismo, señala tanto el problema de la inconsistencia en el comportamiento que pueda surgir de la presencia de normas controvertidas o antagonistas como la cuestión del papel e influencia de los Estados miembros en la acción exterior de la UE. Por último, se detiene en la posición problemática de la potencia normativa como compromiso 
académico, en particular con respecto a si dicha teoría tiene un componente explicativo, descriptivo o normativo. Esta última consideración no posee sustento crítico suficiente en tanto que el propio Manners señala en repetidas ocasiones que su planteamiento teórico se construye desde una voluntad no solo descriptiva sino crítica y por lo tanto prescriptiva. Un enfoque de poder normativo rechaza cualquier tentación dirigida hacia un análisis irreflexivo y no crítico (Manners, 2006, 65).

El conflicto en torno al peso de las normas y los intereses en la formulación de la acción exterior de la UE ha generado amplios debates académicos. En conjunto, la literatura ha reafirmado la validez del marco de "poder normativo" (por ejemplo, Nicolaïdis y Whitman, 2013) y con ello el supuesto de que la UE está predispuesta a actuar de manera normativa debido a su particular historia y construcción normativa (Birchfield, 2013). Sin embargo, hay voces que se desvinculan de esta tendencia y plantean nuevas aproximaciones al respecto. Noureddine (2016) considera que el impacto normativo de la UE con respecto a la actuación de terceros actores es muy limitado porque los Estados miembros han priorizado sus propios intereses en detrimento de los valores consagrados por la UE.

Del Sarto (2013), al utilizar el concepto de imperio normativo, pretende superar la dicotomía entre los discursos normativos de la UE y sus políticas basadas en los intereses materiales. De este modo, al actuar bajo la lógica imperial, la exportación de normas y prácticas de la UE a sus Estados vecinos se entiende como la búsqueda de sus propios intereses, que sirve asimismo para la construcción de una identidad "normativa". Se pretende acabar con la falsa dicotomía entre normas e intereses: ambos forman parte de una lógica de actuación integrada (Del Sarto, 2013, 216).

Benjamin Kienzle (2012) pone el foco en la competición normativa derivada de la actuación de la potencia normativa europea. La UE no solo promueve normas universales relativas a la democracia o a los derechos humanos, sino también algunas que pueden no encajar en esta categorización (Kienzle, 2012, 78). Así las cosas, la UE se enfrenta a un dilema: puede o bien intentar promover todas las normas que representa de una manera coherente y pagar el precio en términos de efectividad de su política exterior o bien tratar de centrarse en una única 
norma y ser objeto de acusaciones de doble estándar (Kienzle, $2012,77)$. En lo que respecta al caso iraní la UE ha optado por la promoción exclusiva de las normas relacionadas con régimen de no proliferación nuclear, sin mostrar implicación efectiva en el fomento de estructuras normativas vinculadas con los derechos humanos y la democracia liberal. De esta forma, al priorizar qué normas se promueven con respecto a otras, la UE también actúa como potencia normativa puesto que determina sus preferencias en términos de sostenibilidad internacional. La UE prefiere un Irán estable y lejano de convertirse en una potencial con capacidad nuclear real en Oriente Medio.

Esta competencia normativa deviene capital para el posterior estudio de los elementos normativos introducidos por la UE en el caso iraní. Establece los límites explicativos que ofrece la aproximación de potencia normativa europea puesto que solo resultará pertinente para el examen de la normalidad que la UE haya tratado de difundir. Mediante la promoción efectiva de un único tipo de normas, la UE conseguirá afianzar su rol normativo a expensas de renunciar a la promoción de otras normas que considera también componentes esenciales de su identidad. Solo nos podremos referir a la UE en tanto que potencia normativa si focalizamos la mirada a una norma exclusiva, que la UE promociona de forma deliberada. Algunos autores, desde una óptica funcionalista, podrían referirse a esta labor normativa parcial como el inicio de una cascada normativa; sería como la apertura del actor que se ve influenciado por la UE hacia la totalidad de la normalidad internacional. Sin embargo, si bien las normas diferentes pueden no contradecirse, la promoción de una en concreto no tiene por qué llevar al alineamiento con otras, que además formen parte de otros regímenes internacionales. Para que este trasvase normativo se produjese se necesitaría una condicionalidad firme que vinculara ambos espacios normativos.

\section{La UE durante el proceso negociador con Irán}

La UE ha participado de forma activa en la resolución del conflicto iraní. El siguiente apartado analiza las diversas posturas y modalidades negociadoras que la UE ha mostrado a lo largo del proceso. 


\subsection{El E3 como negociador autónomo (2003-2005)}

La comunidad internacional descubrió en 2002 que Irán venía desarrollando desde hacía más de una década un programa nuclear secreto. En 2003 tres ministros de Asuntos Exteriores europeos, Dominique de Villepin de Francia, Jack Straw de Reino Unido y Joschka Fischer de Alemania, conocidos como E3, enviaron una carta a Teherán ofreciendo cooperación técnica y comercial a cambio de que Irán paralizase su enriquecimiento de uranio y aplicase el Protocolo Adicional del Organismo Internacional de Energía Atómica². Los tres Estados miembros mantenían un mismo discurso, que era además el de la UE (Santini, 2010, 474). La nueva visión europea de la seguridad, recogida en la Estrategia Europea de Seguridad de 2003, recogía las líneas de actuación con respecto a la no proliferación, en consonancia con el derecho internacional y el régimen de NNUU. El enfoque del E3 era desde el principio claro en sus demandas y ofertas diplomáticas e incorporó el llamamiento del alto representante para la PESC Javier Solana al "multilateralismo efectivo". La posición iraní contemplaba el desarrollo de su programa nuclear como un "derecho inalienable" derivado del Artículo IV del Tratado de No Proliferación de Armas Nucleares (TNP)4 de 1968.

A fines de 2003 el Alto Representante Javier Solana se integró en el grupo negociador, que pasó a denominarse EU3. Esta inclusión, además de imprimir un carácter más formal a la presencia de la UE en las negociaciones, respondía a las demandas de las instituciones comunitarias, que se sentían insatisfechas con la naturaleza restrictiva del E3 (Santori, 2010, 475). En octubre de 2004 se firmó en París un acuerdo entre la

2 El Protocolo Adicional al acuerdo de salvaguardias del TNP otorga a los inspectores del OIEA mayor autoridad para verificar el programa nuclear de un país determinado. También requiere que los Estados proporcionen una declaración ampliada de sus actividades nucleares y otorga al Organismo derechos más amplios de acceso a las instalaciones en el país.

3 La Estrategia Europea de Seguridad supuso el primer intento y referente de visión y estrategia global común de la UE, elaborada en una coyuntura de ausencia de acción común a raíz de la guerra de Irak como elemento de superación de esta y referente desde entonces en el discurso, el posicionamiento y la acción exterior de la UE. El multilateralismo efectivo se ha convertido en parte recurrente del discurso, mantra de la acción exterior europea (Montobbio, 2013).

4 EI TNP, en vigor desde 1970, tiene el objetivo fundacional de prevenir la diseminación del armamento nuclear, y contiene acuerdos en materia de no proliferación, desarme, energía nuclear y zonas libres. Básicamente obliga a los países firmantes a renunciar a la posesión de este tipo de armamento, con la excepción de los países del Consejo de Seguridad de la ONU, a quienes conmina vagamente a hacer pasos hacia el desarme. Irán forma parte de este. 
UE e Irán mediante el cual Teherán suspendía su enriquecimiento voluntariamente de forma temporal mientras que la UE reconocía el derecho iraní al desarrollo de un programa nuclear pacífico, rechazando elevar el caso iraní a instancias del Consejo de Seguridad de Naciones Unidas (CSNNUU). Asimismo, Irán firmó y acordó implementar (aunque no ratificar) el Protocolo Adicional a su acuerdo de salvaguardias del OIEA.

\subsection{La UE como coordinadora (2006-2010)}

En enero de 2006 Irán denegó el acceso a oficiales del OIEA a sus instalaciones de Natanz y de Isfahan, lo que reanudó la investigación sobre el enriquecimiento de uranio. Como respuesta a Irán el Consejo Europeo emitió una declaración en la que se refirió a la decisión de Irán de reiniciar el enriquecimiento como "un claro rechazo" del proceso en el que el EU3 e Irán habían estado comprometidos durante dos años y concluyó que las negociaciones habían llegado a un punto muerto. Había llegado el momento de que el Consejo de Seguridad se involucrase "para reforzar la autoridad de las resoluciones del OIEA" (E3 y AR, 2006).

A principios de 2006 el EU3 se amplió con la incorporación de Estados Unidos, Rusia y China. El formato pasó a ser el de EU3+3 o P5 $+1^{5}$. Este movimiento respondía a la voluntad de ampliar la legitimidad internacional del grupo negociador ad hoc (Santini, 2010, 479). El EU3+3 se comprometió a suspender las discusiones en el Consejo de Seguridad si Irán acababa con todas las actividades de enriquecimiento y reprocesamiento. Teherán rechazó la propuesta. En julio el Consejo de Seguridad adoptó la Resolución 1696, refiriéndose a la suspensión de "todas las actividades de enriquecimiento y reprocesamiento" como "obligatorias" en virtud del Capítulo VII de la Carta de las Naciones Unidas (Consejo de Seguridad, 2006). Esta resolución marcó una nueva fase; los cinco miembros permanentes mostraban una posición común, si bien es cierto que tanto Rusia como China destacaron que la referencia al Capítulo VII no suponía un mandato para la acción militar.

A finales de 2006, el Alto Representante Javier Solana y el líder del equipo negociador iraní, Ali Larijani, discutieron el establecimiento de cooperación en investigación e incluso sobre

5 Hace referencia a la actuación conjunta de los cinco miembros permanentes del CSNNUU más Alemania. 
el enriquecimiento a escala piloto. En diciembre de 2007, Estados Unidos publicó un documento que concluía que Irán estaba en posesión de un programa estructurado de armamento nuclear desde 2003. Ese mismo informe señalaba la voluntad iraní de mantener sus opciones abiertas y buscar las posibilidades de desarrollar y construir armas nucleares.

El P5 + 1 continuó buscando negociaciones con Irán y fue responsable de ofrecer propuestas concretas, dando seguimiento a las negociaciones anteriores del E3. La UE era el coordinador del P5 + 1 y tenía el importante papel de prevenir el uso del veto por parte de cualquier miembro permanente del Consejo de Seguridad. Aunque el Consejo de nunca formalizó un mandato para los negociadores, sus resoluciones respaldaron el rol de P5 + 1 y el papel de la UE dentro de él. Más allá de servirse del marco de NNUU para reforzar su influencia, la UE estaba actuando para preservar el derecho internacional (Jorgensen, 2009, 46-47).

\subsection{La UE como promotora de las sanciones (2010-2013)}

La victoria de Barack Obama y su elección como presidente de los Estados Unidos abría una nueva ventana de posibilidad en la resolución del conflicto iraní, dadas sus declaraciones durante la campaña electoral relativas a su voluntad de negociar con Irán. En septiembre de 2009, Obama, junto con el primer ministro británico, Gordon Brown, y el presidente francés, Nicolas Sarkozy, revelaron el comienzo de la construcción de una nueva instalación de enriquecimiento cerca de la ciudad de Qom. El mes siguiente, los estadounidenses, junto con los rusos y los franceses, se reunieron directamente con los iraníes por primera vez, bajo la presidencia del OIEA. El denominado "Grupo de Viena" propuso llevar el 75 por ciento del uranio poco enriquecido iraní fuera del país para enriquecerlo a un nivel adecuado para uso civil en Irán. El acuerdo no llegó a materializarse, principalmente debido a la oposición doméstica iraní.

Posteriormente el presidente brasileño Lula da Silva y su homólogo turco Recep Tayyip Erdogan se reunieron con el líder iraní Ahmadinejad en mayo de 2010 y firmaron la Declaración de Teherán, en la que Irán se comprometía a enviar su uranio a Turquía, que sería retornado a Irán como barras de combustible 
para el reactor de investigación en el plazo de un año. Para sorpresa del ejecutivo brasileño, Washington rechazó esta propuesta porque ya tenía planes alternativos a esas alturas: sanciones adicionales en el seno del Consejo de Seguridad (Cronberg, 2017, 249). El Consejo de Seguridad aprobó la Resolución 1929 en junio de 2010, que establecía medidas restrictivas contra Irán, entre ellas el embargo de su crudo.

El Consejo Europeo (2010) celebró dicha resolución y la UE impulsó sanciones unilaterales paralelas a las procedentes de las Naciones Unidas. Se incluyeron sanciones al comercio, seguros, sector bancario y de transportes, así como una prohibición a las transferencias de inversión y tecnología al sector iraní de hidrocarburos. Asimismo, el Consejo Europeo lamentaba que Irán no hubiese aprovechado las numerosas oportunidades que se le habían brindado para disipar las preocupaciones de la comunidad internacional en lo relativo a la naturaleza de su programa nuclear.

En 2012 la UE prohibió la importación de petróleo y gas de Irán e impuso limitaciones a las transacciones financieras (CAE, 2012). El Consejo Europeo, en las conclusiones de su encuentro el 28 y 29 de junio, acogió con satisfacción la plena entrada en vigor del embargo sobre el crudo iraní y señalaban la voluntad resuelta de la UE de seguir presionando a Irán mientras no cambiase su postura, en estrecha coordinación con sus socios internacionales. El papel de la UE en esta fase fue más contundente de lo que había sido anteriormente.

\subsection{La UE como facilitadora (2013-2015)}

La elección presidencial iraní de 2013 supuso un gran avance en el desarrollo de las negociaciones. La victoria fue para el pragmático y moderado Hassan Rouhani, muy familiarizado con el problema nuclear puesto que fue negociador principal de Irán entre 2004 y 2006. El líder supremo Khamenei ya había aprobado en 2011 las negociaciones bilaterales entre Irán y Estados Unidos mediadas por el Sultán de Omán. Se acordó llegar primero a un acuerdo interino seguido de uno definitivo. Tanto Irán como Estados Unidos tenían sus propuestas listas en octubre de 2013. 
El Plan de Acción Integral Conjunto (PAIC), el acuerdo interino, se concluyó el 24 de noviembre de 2013. Según el mismo, Irán acordaba no hacer avanzar sus actividades nucleares y eliminar todo su uranio enriquecido. El P5 + 1 e Irán acordaron un proceso de dos etapas para alcanzar una solución integral a largo plazo y mutuamente garantizaban que el programa nuclear de Irán sería exclusivamente pacífico. El 2 de abril de 2015 se concluyó un acuerdo marco que cubría los parámetros clave para un acuerdo final. El acuerdo final se concluyó el 14 de julio de 2015. Las negociaciones bilaterales no podrían haber sido posibles sin el marco del P5 +1 . Irán señalaba al P5+1 como interlocutor fundamental en la consecución del acuerdo. Así pues, durante la fase bilateral, la UE se convirtió en un facilitador práctico (Cronberg, 2017, 251).

El Consejo, en sus conclusiones del 20 de julio de 2015, definió la consecución de este acuerdo como un momento histórico. Sus conclusiones también ponían en valor la labor de coordinación desempeñada por la Alta Representante, así como el compromiso de Francia, Reino Unido y Alemania desde la puesta en marcha de las negociaciones en 2003. El Consejo confiaba en el buen desarrollo del acuerdo y en la capacidad de este para servir como base de un contexto regional más estable y seguro. Asimismo, el acuerdo se contempló como una herramienta potencialmente efectiva en la normalización de las relaciones de Irán con la UE y sus Estados miembros y se estimó como "un elemento clave de la arquitectura global de la no-proliferación nuclear y crucial para la seguridad de la región" (Consejo, 2017).

\subsection{La retirada de EE. UU. y sus consecuencias}

El 16 de enero de 2016, ya con el PAIC en vigor, el Consejo Europeo anuló todas las sanciones económicas y financieras contra Irán que estaban vinculadas a la cuestión nuclear. No obstante, algunas sanciones, las relativas a cuestiones de derechos humanos, continúan vigentes (Argano, 2018). La retirada de las sanciones ha facilitado las relaciones económicas y comerciales entre la UE e Irán. En 2016 las importaciones desde Irán alcanzaron los 5.500 millones de euros, un aumento del 344,8\%, mientras que las exportaciones de la UE ascendieron a 8.200 millones, un aumento del $27,8 \%$. 
En 2017 las importaciones de Irán superaron los $10.1 \mathrm{mil}$ millones y las exportaciones a Irán alcanzaron un máximo de 10.8 mil millones (SEAE, 2018). Asimismo, son numerosas las declaraciones y pronunciamientos realizados desde las instituciones comunitarias en apoyo del PAIC.

El 8 de mayo de 2018 el presidente estadounidense Donald Trump anunció que su país se retiraba del acuerdo alcanzado con Irán y procedía a la reintroducción de medidas sancionadoras. La alta representante de la UE para la PESC, Federica Mogherini, respondió de inmediato que el acuerdo nuclear pertenecía a toda la comunidad internacional y que la UE estaba decidida a preservarlo (EEAS, 2018). A pesar de ello, es evidente que la decisión estadounidense tiene repercusiones directas sobre el propio acuerdo. La UE se configura como uno de los actores más involucrados en esta disputa: el respeto de Irán al acuerdo está en estrecha relación con la capacidad europea de mantener las relaciones económicas, energéticas y comerciales con Teherán (Argano, 2018). En consecuencia, la UE ha tomado dos importantes medidas con objeto de proteger sus compañías de las sanciones secundarias y sus vínculos comerciales con Irán.

La UE ha reactivado su Reglamento de bloqueo, que impide que las empresas europeas cumplan con las solicitudes de los EE. UU. y exime a los sujetos europeos de las decisiones judiciales y de las autoridades administrativas fuera de la UE. Sin embargo, según Annalisa Perteghella (2018), el Reglamento tiene más valor político que económico ya que los EE. UU. tienen el poder de excluir a las instituciones financieras internacionales que tienen relaciones con Irán de su sistema financiero. Asimismo, la UE incluyó a Irán en la lista de países elegibles para préstamos del Banco Europeo de Inversiones y ha habilitado una herramienta de pago que ayudará a las entidades europeas que deseen mantener relaciones económicas con Irán, lo que mitiga el efecto de las sanciones impuestas por Estados Unidos.

\section{Elementos normativos en el caso iraní}

Veamos a continuación cuál ha sido la dimensión ética de la potencia normativa europea en la promoción de los principios de Estado de derecho internacional y paz sostenible en el caso iraní. Se toma por válida la premisa de que la exportación y 
consolidación del régimen internacional de no proliferación ha preponderado en la competencia normativa frente a la normalidad internacional ligada al régimen de derechos fundamentales. Un Irán desvinculado de cualquier ánimo nuclear con carácter militar es crucial para mantener la sostenibilidad dentro de la región. Así las cosas, la UE da prioridad a la seguridad y al hacerlo también actúa como potencia normativa. Ante una disyuntiva que no permite una promoción integral de toda la batería normativa propia de la identidad europea, decidir qué elementos normativos aventajan a otros es decidir qué tipo de potencia normativa se está escogiendo ser bajo los condicionantes referidos.

La UE ha actuado bajo el principio de "vivir con el ejemplo" en el caso iraní en tanto que se halla en consonancia con los principios del régimen de no proliferación. Los Estados miembros de la UE suscriben el TNP y respetan sus disposiciones. Este hecho ha dotado a la UE de legitimidad a la hora de realizar exigencias o recriminar falta de compromiso a Irán. Por tanto, la UE ha mostrado una postura coherente con respecto al caso iraní y en consonancia con la de sus Estados miembros. Prueba de ello es la diversidad de modalidades en la participación de Europa en las distintas fases negociadoras, que siempre ha mantenido un mismo propósito final.

La UE se muestra comprometida con la participación en el diseño del régimen de no proliferación y con su exportación. El PAIC da buena cuenta de ello ya que ha supuesto la constatación de la voluntad de la UE de involucrarse en la instauración de una modalidad de Estado de derecho supranacional a través de su sustento al multilateralismo efectivo. Esta defensa del multilateralismo se basa en la idea apoyada por la UE de que los regímenes internacionales son la herramienta más efectiva para la universalización de las relaciones entre la sociedad internacional y determinados actores. EL PAIC, como producto normativo, es el instrumento que ha de permitir a Irán normalizar su situación en el seno de la sociedad internacional.

Por último, la UE consigue "vivir por ejemplo" en la medida en que dota de trascendencia al proceso negociador y al acuerdo resultante. Al considerarlo un hito para su diplomacia, se otorga protagonismo en la consecución del acuerdo y refuerza su imagen como actor internacional relevante. Más allá de cuál haya sido su rol real en la consecución del PAIC, la UE logra proyectarse como una potencia normativa. 
Bruselas ha sido "razonable" en el caso iraní al realizar llamamientos constantes al diálogo y a la negociación. La UE no solo se compromete a trabajar por el establecimiento de canales de diálogo con Irán sino que reconoce el esfuerzo de actores terceros que trabajan por en la misma dirección. La UE ha tratado de ejercer presión sobre Irán a través de las diversas rondas de sanciones provenientes del CSNNUU así como a través de las impulsadas desde Bruselas. Estas sanciones han pretendido no socavar el diálogo sino potenciarlo, por lo que la UE ha mostrado en la totalidad del proceso un férreo impulso negociador. La UE ha mostrado compromiso con los espacios de negociación creados y con los logros surgidos de los mismos.

La institucionalización de los procesos negociadores ha supuesto asimismo un refuerzo de la actuación "razonable" de la UE puesto que ha conseguido apuntalar los estadios relativos a las negociaciones. Irán ha acabado por aceptar elementos que, sin ser considerados como cercanos, resultaba necesario asimilase para obtener un desarrollo exitoso de las negociaciones. Este hecho se ha visto reforzado por la asimetría en las negociaciones. Irán se ha visto muy limitado en su capacidad negociadora, además de limitarse por la presencia de EE. UU. y la UE, por la existencia de un régimen internacional consolidado que no cuenta con presiones revisionistas de envergadura. Esta característica ha ayudado de igual modo a robustecer la actuación de la potencia normativa europea ya que se ha dado en un entorno de aceptación generalizada por parte de la sociedad internacional de las normas para exportar y del régimen que las contiene.

Bruselas ha tratado de "hacer el menor daño" al oponerse a lo largo de todo el conflicto con Irán a cualquier atisbo de intervención militar. La UE consideraba las sanciones impuestas a Teherán como una herramienta encaminada a evitar el uso de la violencia en el desarrollo de los acontecimientos. El carácter temporal que la Unión ha tratado de imprimir a las sanciones en todo momento puede ubicarse dentro de su voluntad de no perjudicar de forma sobrante a Irán. Bruselas, en cada uno de sus anuncios de sanciones, ha depositado la responsabilidad de estas en la negativa de Irán a asumir sus compromisos y retomar el diálogo.

La UE se ha encargado de presentar el PAIC como un acuerdo de consecuencias positivas para la sociedad iraní. La noción de prosperidad económica y social ligada al acuerdo supone un 
elemento capital del mismo. Al renunciar a su programa nuclear, Irán apuesta por proveer una mejor vida a sus ciudadanos. Se transmite de nuevo el mensaje de que la normalización de las relaciones de un actor internacional determinado le asegura mejores condiciones materiales. La UE considera el PAIC no solo positivo para Irán sino para toda la región. Se dota al acuerdo de un carácter estabilizador con consecuencias positivas para la sociedad internacional en su conjunto. El PAIC se ubica en una política integral para con Oriente Medio, que pasa por una necesaria paz sostenible y perdurable.

Por último, la UE reconoce los esfuerzos iraníes a la hora de cumplir con las disposiciones del PAIC. La Unión cierra el círculo del proceso de su actuación normativa al poner en valor que Irán esté avanzando en la dirección que se la ha señalado. Dicho esfuerzo debe ser, según la $U E$, recompensado con el mantenimiento y la defensa del pacto frente a las posibles amenazas con que se encuentre. Se ha establecido una relación normativa recíproca, de promoción y exportación de normas hacia un actor determinado y de apropiación y defensa de los resultados positivos procedentes desde dicho actor.

\section{Conclusiones}

Según lo expuesto, se puede concluir que la UE ha actuado como potencia normativa en el caso iraní, pero únicamente en la promoción y exportación de la normalidad internacional relativa al régimen de no proliferación nuclear. La Unión ha priorizado dicho ámbito normativo frente al régimen de derechos humanos, que no ha formado parte de las prioridades normativas europeas. Esta focalización selectiva de los componentes normativos para promocionar le ha permitido a la UE aumentar su efectividad, pero reduce su legitimidad global como potencia normativa puesto que pone en evidencia su incapacidad para presentar una actuación normativa integral que resulte exitosa. Esta apuesta por una actuación normativa parcial puede ser concebida de igual modo como una muestra de actuación normativa: la UE ayuda a decidir qué normas deben ser priorizadas en la esfera internacional.

Asimismo, Bruselas imprime a su actuación un carácter pragmático al apostar por la promoción del régimen de no proliferación. En primer lugar, este goza de mayor consenso en 
el seno de la sociedad internacional y la UE presenta una mayor coherencia performativa a la hora de promover dicho régimen. Por otro lado, dicho régimen es considerado además una llave de acceso a la estandarización de relaciones de un actor en el sistema internacional. La UE plantea de este modo la alineación efectiva de Irán con el régimen de no proliferación nuclear como el primer paso dentro de una senda progresiva de modificaciones políticas, económicas y sociales. Por último, las cuestiones de no proliferación permiten a Bruselas presentarse como un actor relevante en la configuración de la seguridad global.

La UE ha introducido, de entre los nueve que propone Manners, sus elementos normativos de paz sostenible y Estado de derecho supranacional en el caso iraní. El carácter trasversal del PAIC lo dota precisamente de un componente sostenible en tanto que se trata de una solución con voluntad duradera. La existencia de regímenes internacionales supone la construcción de un Estado de derecho supranacional; construcción que la UE promociona y de la que participa. La UE es definida como un espacio densamente normativo que se rige por el respeto comprometido al Estado de derecho. Dicho alineamiento se traduce en la voluntad de su política exterior de dotar al escenario internacional de elementos normativos que lo regulen. Se han podido asimismo identificar elementos éticos en la introducción de estos dos principios. Así pues, la UE ha actuado en virtud del ejemplo siendo razonable y tratando de hacer el menor daño en la promoción del régimen de no proliferación en el caso iraní.

Todo ello lleva a concluir que el caso iraní ha permitido a la UE mantener su posicionamiento de potencia comprometida con el multilateralismo. A pesar de la pérdida de influencia que la UE ha sufrido en el contexto internacional, la Unión sigue manteniendo la defensa del multilateralismo como uno de los ejes constitutivos de su acción exterior. El caso iraní, presentado por las instituciones comunitarias como un éxito diplomático, es utilizado por la UE para apuntalar dicho compromiso y para presentarse ante el resto de la comunidad internacional como un actor de relevancia; es decir, como una potencia normativa. 


\section{Referencias}

Birchfield, V. (2013). A Normative Power Europe Framework of Transnational Policy Formation. Journal of European Public Policy, 20 (6), pp. 907-922.

Consejo de la Unión Europea. (30 de noviembre y 1 de diciembre de 2011). 3130th Council Meeting Foreign Affairs [Comunicado de prensa]. Recuperado de www. consilium.europa.eu/uedocs/cms_data/docs/pressdata/EN/foraff/126518.pdf

Consejo de la Unión Europea. (24 de enero de 2012). Council Decision 2012/35/ CFSP of January 23, 2012, amending Decision 2010/413/CFSP concerning restrictive measures against Iran. Official Journal of the European Union. Recuperado de http://eur-lex.europa.eu/LexUriServ/LexUriServ.do?uri=OJ:L:2012:019:0022:0030:EN:PDF

Consejo de la Unión Europea. (28 de mayo de 2018). Outcome of the Council Meeting. 3621st Council meeting Foreign Affairs [Comunicado de prensa].

Consejo Europeo. (12 de diciembre de 2003). European Security Strategy: A Secure Europe in a Better World.

Consejo Europeo. (23 de octubre de 2011). Conclusiones. [Comunicado de prensa].

Consejo Europeo. (18 y 19 de octubre de 2012). Conclusiones. [Comunicado de prensa]. Consejo Europeo. (19 de octubre de 2017). Conclusiones. [Comunicado de prensa].

Cronberg T. (2017). No EU, no Iran deal: the EU's choice between multilateralism and the transatlantic link. The Nonproliferation Review, 24 (3-4), pp. 243-259.

De Zutter, E. (2010). Normative Power Spotting: An Ontological and Methodological Appraisal. Journal of European Public Policy, 17 (8), pp. 1106-1127.

Diario Oficial de la Unión Europea. (2007). Tratado de Lisboa, C 306/01.

Diez, T. (2013). Normative power as hegemony. Cooperation and Conflict, 48 (2), pp. 194-221.

Erickson, J. L. (2011). Market Imperative Meets Normative Power: Human Rights and European Arms Transfer Policy. European Journal of International Relations, 19 (2), pp. 209-234.

Hyde-Price, A. (2008). A 'tragic actor'? A realist perspective in 'ethical power Europe'. International Affairs, 84 (1), pp. 29-44.

Jorgensen, K. E. (2009). The EU and International Organizations. London: Routledge.

Kienzle, B. (2009). The EU strategy against proliferation of WMDs: an interim assessment. CFSP Forum, 4 (49), pp. 1-4.

Kienzle, B. (2012). Between Human Rights and Non-proliferation: Norm Competition in the EU's Iran policy. UNISCI Discussion Papers, (30), pp 77-91.

King, T. (1999). Human Rights in European Foreign Policy: Success or Failure for Post-Modern Diplomacy. European Journal of International Law, 19 (2), pp. 313-337.

Manners, I. (2002). Normative Power Europe: A Contradiction in Terms? Journal of Common Market Studies, 40 (2), pp. 235-258.

Manners, I. (2006). The Constitutive Nature of Values, Images and Principles in the European Union. Values and Principles in European Union Foreign Policy. London: Routledge, pp. 19-41.

Manners, I. (2008). The normative ethics of the European Union. International Affairs, $84(1)$, pp. 45-60.

Nicolaïdis, K. \& Nicolaïdis, D. (2006) The EuroMed beyond Civilisational Paradigms. The Convergence of Civilizations: Constructing a Mediterranean Region. Toronto: University of Toronto Press, pp. 348-349.

Noureddine, R. (2016). Normative Power Europe and in Field of Human Rights: is the EU a force for Good in the World? Australia and New Zealand Journal of European Studies, 8 (2), pp. 111-118.

O'Neill, O. (2000). Bounded and Cosmopolitan Justice. Review of International Studies, 26 , pp. $45-60$.

Perteghella, A. (2018). USA fuori dall'Iran deal: business europeo alla prova. ISPI, Recuperado de: https://www.ispionline.it/it/pubblicazione/usa-fuori-dalliran-deal-business-europeo-alla-prova-20869 
La potencia normativa europea en relación con el caso iraní entre 2010 y 2017: el Plan de Acción Integral Conjunto

Rafati, N. \& Vaez, A. (4 de febrero de 2019). Europe Tests the Boundaries on Iran: A New Trade Vehicle Could Preserve the Nuclear Deal's Core Bargain. Foreign Affairs. Recuperado de https://www.foreignaffairs.com/articles/iran/201902-04/europe-tests-boundaries-iran?utm_edium =newsletters\&utm_source $=$ fatoday\&utm_content $=20190610 \& u t m \_$campaign $=F A \% 20$ Today $\% 20$ 061019\%20Lessons\%20for\%20Algeria\%20and\%20Sudan\%2C\%20Repression $\% 20$ in $\% 20$ China $\% 2$ C $\% 20$ Trade $\% 20$ With\%20Iran\&utm_term=FA\%20 Today\%20-\%20112017

Resolución 1696 de 2006. Consejo de Seguridad de Naciones Unidas, 31 de julio de 2006. Santini, R. H. (2010). European Union Discourses and Practices on the Iranian Nuclear Programme. European Security, 19 (3), pp. 467-489.

Servicio Europeo de Acción Exterior. (8 de mayo de 2018). Iran and the EU. Recuperado de https://eeas.europa.eu/headquarters/headquarters-homepage/2281/ iran-and-eu_tk

Servicio Europeo de Acción Exterior. (14 de julio de 2015). Joint Comprehensive Plan of Action. Recuperado de http://eeas.europa.eu/archives/docs/statements-eeas/ docs/iran_agreement/iran_joint-comprehensive-plan-of-action_en.pdf

Servicio Europeo de Acción Exterior. (2016). Shared Vision, Common action. A Stronger Europe: A Global Strategy for the European Union's Foreign and Security Policy. Recuperado de http://eeas.europa.eu/archives/docs/top_stories/pdf/ eugs_review_web.pdf

Servicio Europeo de Acción Exterior. (15 de mayo de 2018). Remarks by HR/VP Mogherini at the press conference following ministerial meetings of the EU/ E3 and EU/E3 and Iran. Recuperado de https://eeas.europa.eu/headquarters/ headquarters-homepage/44599/remarks-hrvp-mogherini-press-conference-following-ministerial-meetings-eue3-and-eue3-and-iran_en

Statement by Germany, United Kingdom, France and the EU High Representative on the Iranian nuclear issue. (12 de enero de 2006).

Solana, J. (8 de septiembre de 2006). Europe's answers to the global challenges. Discurso para la Universidad de Copenhague, Copenhague: Dinamarca.

Barbé, E. y Johansson-Nogués, E. (enero de 2008). The Eu as a Modest 'Force for Good: the European Neighbourhood Policy. International Affairs, 84, pp. 81-96.

Tabatabai, A. (20 de septiembre de 2017) Does the Iran Nuclear Deal Have a Future? Why Europe's Continued Support Is Key. International Affairs. Recuperado de https://www.foreignaffairs.com/articles/persian-gulf/2017-09-20/ does-iran-nuclear-deal-have-future

Whitman, R. G. (Ed.). (2011). Normative Power Europe: Empirical and Theoretical Perspectives. Basingstoke: Palgrave Macmillan. 